\title{
Assessment or Evaluation of Genetic Diversity among 66 Cultivars of Chickpea (Cicer arietinum L.) of Indian Origin Using SSR Markers
}

\author{
Harshika Aggarwal, Shiv Pratap Choudhary*", M.K. Rana and R. Choudhary \\ National Bureau of Plant Genetic Resources (NBPGR), Pusa campus, \\ New Delhi 110012, India \\ *Corresponding author
}

\begin{tabular}{|l|}
\hline Ke y w o r d s \\
Chickpea, Genetic \\
Diversity, SSR \\
Markers, \\
Polymorphic, \\
Germplasm
\end{tabular}

\section{Introduction}

Chickpea (Cicer arietinum L.) is the third most important winter season [diploid plant $(2 \mathrm{n}=2 \mathrm{x}=16)]$ self pollinated with an estimated haploid genome size of $738 \mathrm{Mb}$ pulse crop (Varshney et al., 2013). Two main types of cultivated chickpea are Kabuli (white seeded) and desi (brown seeded), representing
The exploration of genetically variable accessions is the key source of germplasm conservation and potential breeding material for the future. The more diverse group of cultivars provides an ample opportunity to breeders for re-leasing new and superior varieties, considering their quality traits for direct commercial utilization. In this study, we analyzed genetic structure, diversity and relationships in 66 accessions of Cicer arietinum using SSR molecular markers. A total of 44 PCR based SSR primers were used for molecular characterization of 66 accessions. These primers found to be polymorphic genetic diversity among local and exotic accessions. A total of 66 different reproducible bands were amplified, most of them are polymorphic. The number of bands per primer ranged from 2 to 7 with an average of 3.88 bands per primer. The size of amplified products ranged from $60 \mathrm{bp}$ (CICER CAST MS2) to $400 \mathrm{bp}$ (CICER TA 28). Maximum numbers of polymorphic bands (7) were obtained with the primers viz., CICER TA 22 and CICER TA 28. Whereas, similarity index of pair-wise comparisons estimated on the basis of all the 66 primers ranged from 0.43 to 0.97 . Highest genetic similarity $(0.97)$ showed between DFP02-7024 and DFP02-7024; DFP02-7047 and DFP02-7048, indicating that they are genetically quite similar, whereas DFP02-7041 showed least similarity (0.43). Genetic variability of primers was scored by cluster analysis through UPGMA per-cent disagreement. Most of the diversity was confined to the wild species, which had higher values of polymorphic information content, gene diversity and heterozygosity than the cultivated species, suggesting a narrow genetic base for cultivated chickpea. 
(Saeed et al., 2011). The chickpea seed is a good source of carbohydrates and proteins, which collectively constitute $80 \%$ of the total dry seed weight (Aggarwal et al., 2013). Chickpea is also an important food for people to use to improve major food-related health problems (Jukanti et al., 2012).

Recently, developed molecular marker techniques are using for improve molecular breeding because conventional breeding approaches have not greatly improved yield. The knowledge of genetic diversity has a significant impact on the improvement of crop plants and this information has been successfully used for efficient germplasm management, fingerprinting and genotype selection. Genetic diversity can be estimated using phenotypic identification or molecular markers. Molecular markers have proved to be valuable tools for the characterization and assessment of genetic variability within and between species and populations (Talebi et al., 2008). Simple sequence repeats (SSRs) are common and informative molecular markers used for genetic diversity studies because of their simplicity, high levels of polymorphism, high reproducibility, and co-dominant inheritance patterns (Powell et al., 1996).

Various molecular markers are available for the identification of cultivars and analysis of genetic diversity. The random amplified polymorphic DNA (RAPD) marker system has been used for evaluating genetic diversity in chickpea (Sudupak et al., 2002). However, little genetic diversity was detected using RAPD markers (Singh et al., 2002). Inter simple sequence repeats (ISSR) markers are more consistent than the RAPD markers, asthey generate a greater number of polymorphic loci per primer (Aggarwal et al., 2011). Unlike RAPDs, ISSR markers are detected using longer semiarbitrary SSR primers at highly stringent conditions in PCR; therefore, they are reproducible and highly polymorphic DNA markers (Alam et al., 2009). In addition to these applications, cultivated chickpea has low level of genetic polymorphism. However, now availability of large number of microsatellite markers is offering immense scope in assessing the diversity and of utilizing the diverse lines in map construction. They also provide new insights into genome analysis, help in germplasm characterization, phylogenetic analysis and genetic diagnostics. It is important to characterize the genetic diversity in plant species since they serve as a resource base for as yet unidentified genetic information. Germplasm collections needs to be analyzed using for estimating the genetic variability.

The present study was thus undertaken to analyze the nature of genetic structure and the level of genetic diversity and relationships within and between the popular chickpea cultivars and breeding lines and two of its closest wild relatives using a wide set of SSR markers. The study can supply information about putative domestication events, evolutionary relationships and the gene flow between the cultivated chickpea and its wild relatives and will therefore provide opportunities for breeders and molecular biologists to use diverse accessions for varied applications in chickpea genomics and breeding.

\section{Materials and Methods}

\section{Plant materials}

A total of 66 chickpea accessions collected from different regions of India used for the present study (Table 1). Seeds were collected from Gene Bank of ICAR-National Bureau of Plant Genetic Resources, New Delhi, India. Seeds were germinated in aseptic condition and grown on germination paper (towel paper). Fresh young leaf tissues were collected 
from 15 days old seedling in the winters for further experimental use.

\section{DNA isolation}

Fresh young leaf samples of 15 days old seedlings were used as the source of Genomic DNA. Leaf tissues were ground to a fine paste using mortar and pestle in presence of liquid Nitrogen. For DNA isolation, we used the modified CTAB method (Saghai-Maroof et $a l .$, 1984). Isolated DNA air dried and kept in $200 \mu \mathrm{l}$ of TE buffer. Concentrations of DNAs were determined using spectrophotometer (Nanodrop, Biowave Flourimeter) after DNA isolation.

\section{DNA Purification and Quantification}

Pre-heated RNAase $\left(10 \mu \mathrm{l}\right.$ at $\left.100^{\circ} \mathrm{C}\right)$ were added in $1 \mathrm{ml}$ of isolated DNA sample, then it was incubated at $37^{\circ} \mathrm{C}$ for 1 hour and shaked it periodically, for small interval during incubation period. Equal volume of Phenol: Choloroform: Isoamyl alcohol (25: 24: 1; $\mathrm{v} / \mathrm{v} / \mathrm{v})$ was added. The mixture was then centrifuged at $12000 \mathrm{rpm}$ for 15 minutes and upper aqueous phase (containing the DNA) was transferred to a clean new MCT. DNA was precipitated by using $3 \mathrm{M}$ sodium acetate along with chilled absolute isopropanol (Double volume of DNA). The precipitate was pelleted by centrifugation at $12000 \mathrm{rpm}$ for few seconds. The pellet was then washed with $500 \mu 1$ of $70 \%$ ethanol (for 2 times), air dried and re-suspended in TE buffer (according to quantity of DNA).

\section{Microsatellite Markers and PCR Amplification}

Seventeen SSR primers were used for DNA amplifications using the PCR reaction mixture containing $4 \mu \mathrm{l}$ DNA and $20 \mu \mathrm{l}$ reaction mixture $[2 \mu l \quad$ x10 $\quad$ PCR buffer solution Polymerase chain reaction were done in a volume of $20 \mu \mathrm{l}$ containing $30 \mathrm{ng}$ template DNA, $10 \mathrm{X}$ PCR Buffer, $2.5 \mathrm{mM} \mathrm{MgCl}_{2}$, $0.125 \mathrm{mM}$ dNTPs, $0.75 \mu \mathrm{M}$ of each primer, 5 Unit/ $\mu 1$ of Taq DNA Polymerase and then adjusting the volume with sterilize deioniozed water. The reaction mixture was mixed well and $16 \mu \mathrm{l}$ was distributed to each of 68 tubes. $4 \mu 1$ DNA sample from each genotype was added to corresponding tube, mixed well, and briefly centrifuged to collect drops from wall of tube. Amplification was carried out in a MJ Research PTC-200 Peltier Thermal Cycler for 40 cycles. PCR profile was optimized for amplification by using primers of unique sequence with higher $\mathrm{GC}$ ratio at high stringency. The PCR reaction was carried out with a initial denaturation at $94^{\circ} \mathrm{C}$ for $4 \mathrm{~min}$, final denaturation at $94^{\circ} \mathrm{C}$ for $30 \mathrm{sec}$, annealing at above $50-52^{\circ} \mathrm{C}$ of temperature melting (Tm) for $30 \mathrm{sec}$, and extension at $72^{\circ} \mathrm{C}$ for $30 \mathrm{sec}$, a final extension at $72^{\circ} \mathrm{C}$ for $5 \mathrm{~min}$ and $4^{\circ} \mathrm{C}$ as holding temperature. The amplified PCR products were size separated by $4 \%(w / v)$ metaphor gel with $1 \mathrm{X}$ TAE stained with ethidium bromide and visualized under UV transilluminator and then photographed using Syngene gel documentation system. In order to determine approximated size of bands, 100bp ladder (sigma) was run along with the amplified PCR products. First 44 primers were screened and the best primers were selected for DNA profiling. The scoring of SSR amplicons was done for each genotype.

\section{Scoring and cluster analysis for molecular data}

For each SSR locus, sizes of the alleles were estimated for all the seventeen genotypes and scored in the form of a binary matrix where ' 1 ' represented the presence of a band and ' 0 ' denoted its absence. Pair-wise genetic similarity (GS) was calculated among 66 chickpea genotypes using Jaccard's similarity coefficient. The values of GS may range from 
' 1 ' (identical profiles for all marker in the two genotypes) to ' 0 ' (no common bands). The binary data generated for all the varieties for the polymorphic markers was entered in the Power Marker version 3.25 software. The similarity matrix was used to generate dendrogram for cluster analysis. Cluster analysis was performed on molecular data using the unweighted pair group method using arithmetic means (UPGMA) algorithm, from which dendrograms depicting the similarity among varieties were drawn and plotted using NTSYS-pc. The cophenetic correlation was calculated to find the degree of association between the original similarity matrix and the tree matrix in molecular analyses. Using the Mantel test (Mantel, 1967), a comparison was performed for the accessions by calculating the correlation between the two data sets in NTSYS-pc. Using the same software, PCA was also carried out to identify any genetic association among the germplasms.

\section{Results and Discussion}

The advent of the SSR assay (Powell et al., 1996) provided an efficient method to detect DNA polymorphism and generate a large number of molecular markers for genomic applications. SSR markers are common and informative molecular markers used for genetic diversity studies because of their simplicity, high levels of polymorphism, high reproducibility, and co-dominant inheritance patterns. SSR markers for mapping and analysis of genetic diversity have been reported for a wide variety of plants. All the 66 chickpea genotypes were examined for DNA polymorphism using 17 SSR primers. Out of 17 primers, 16 primers produced amplification whereas, 1 primer viz., CICER CAST MS21did not show any amplification. Out of 16, all the primers showed variable degree of polymorphism ranging from 57.14100 percent. These primers on 66 chickpea genotypes generated 82 total bands out of which 66 were polymorphic and 16 were monomorphic. Electrophoresis pattern of SSR profile was studied on $4 \%(\mathrm{w} / \mathrm{v})$ metaphor gel and only the fragments which were consistently amplified were considered for analysis (Figure 1). Average polymorphism was found to be 82.28 per cent. The DNA amplification and polymorphism generated among various chickpea genotypes using SSR primers are presented (Table 2). Our results represent the comparative information about total number of amplicon amplified by all primers in all chickpea genotypes. The size of amplification products ranged from $60 \mathrm{bp}$ to 400 bp. Primers viz., CICER NCPGR 263, CICER NCPGR 107, CICER TA 14, CICER TA 27, CICER TA 28, CICER TA 71, CICER TA 72, CICER TA 7 and CICER CAST MS2 produced $100 \%$ polymorphism (Table 2 ).

The pairwise Jaccard's similarity coefficient among all of the 66 genotypes ranged from 0.43 to 0.97 . The maximum similarity of 0.97 was observed between genotypes DFP02-7024 and DFP02-7024; DFP02-7047 and DFP027048 , indicating that they are genetically quite similar, whereas DFP02-7041 showed the minimum similarity coefficient of 0.43 . Average similarity across all the genotypes was 0.48 . The dendrogram clearly indicated that DFP02-7041 was most distinct from remaining genotype. The relationship among the genotypes and clearly divided them into five main clusters. The first cluster is biggest cluster and has 55 genotypes. 11 genotypes are present in remaining four clusters. DFP027041 genotype was the distinct from others with similarity value of 0.43 (Figure 2).

Based on Mantel Z-statistics (Mantel 1967), the correlation coefficient (r) was estimated as 0.17 . The $r$ value of 0.17 was considered a good fit of the UPGMA cluster pattern to the data. The two-dimensional plot generated from PCA showed 4 groups that were found to be similar to the clustering pattern of the 
UPGMA dendrogram. In the 2-D plot, genotype DFP02-7041 was also found distinct from all other genotypes. The results of PCA were comparable to the cluster analysis with minor differences. Genotypes grouped within the same cluster in the dendrogram were also occupying the same position in two dimensional and three dimensional scaling based on molecular data (Figure 3). The analysis gave $63 \mathrm{PCs}$, out of which the first 10 PCs contributed $73.30 \%$ of the total variability of the analyzed germplasm. The first 5 PCs accounted for $53.19 \%$ of the total variability; the first 3 accounted for $40.04 \%$ of the variance, in which maximum variability was contributed by the first component (18.07\%), followed by the second (13.62\%) and third $(8.35 \%)$ components (Table 3$)$.

Table.1 List of chickpea cultivars used in the molecular analysis

\begin{tabular}{|c|c|c|c|c|c|}
\hline S.No. & DFP ID & S.No. & DFP ID & S.No. & DFP ID \\
\hline 1 & DFP 027002 & 23 & DFP 027024 & 45 & DFP 027046 \\
\hline 2 & DFP 027003 & 24 & DFP 027025 & 46 & DFP 027047 \\
\hline 3 & DFP 027004 & 25 & DFP 027026 & 47 & DFP 027048 \\
\hline 4 & DFP 027005 & 26 & DFP 027027 & 48 & DFP 027049 \\
\hline 5 & DFP 027006 & 27 & DFP 027028 & 49 & DFP 027050 \\
\hline 6 & DFP 027007 & 28 & DFP 027029 & 50 & DFP 027051 \\
\hline 7 & DFP 027008 & 29 & DFP 027030 & 51 & DFP 02 7001-1 \\
\hline 8 & DFP 027009 & 30 & DFP 027031 & 52 & DFP 027052 \\
\hline 9 & DFP 027010 & 31 & DFP 027032 & 53 & DFP 027053 \\
\hline 10 & DFP 027011 & 32 & DFP 027033 & 54 & DFP 027054 \\
\hline 11 & DFP 027012 & 33 & DFP 027034 & 55 & DFP 027055 \\
\hline 12 & DFP 027013 & 34 & DFP 027035 & 56 & DFP 027056 \\
\hline 13 & DFP 027014 & 35 & DFP 027036 & 57 & DFP 027057 \\
\hline 14 & DFP 027015 & 36 & DFP 027037 & 58 & DFP 027058 \\
\hline 15 & DFP 027016 & 37 & DFP 027038 & 59 & DFP 027059 \\
\hline 16 & DFP 027017 & 38 & DFP 027039 & 60 & DFP 027060 \\
\hline 17 & DFP 027018 & 39 & DFP 027040 & 61 & DFP 027061 \\
\hline 18 & DFP 027019 & 40 & DFP 027041 & 62 & DFP 027062 \\
\hline 19 & DFP 027020 & 41 & DFP 027042 & 63 & DFP 027063 \\
\hline 20 & DFP 027021 & 42 & DFP 027043 & 64 & DFP 027064 \\
\hline 21 & DFP 027022 & 43 & DFP 027044 & 65 & DFP 027065 \\
\hline 22 & DFP 027023 & 44 & DFP 027045 & 66 & DFP 027066 \\
\hline
\end{tabular}


Table.2 Details of amplified bands generated in 66 genotypes chickpea based on 17 SSR primers used for DNA fingerprinting

\begin{tabular}{|c|c|c|c|c|c|c|}
\hline $\begin{array}{l}\text { S. } \\
\text { No. }\end{array}$ & Primer Name & $\begin{array}{l}\text { Size } \\
\text { Range(bp) }\end{array}$ & $\begin{array}{l}\text { Total } \\
\text { no. of } \\
\text { Alleles }\end{array}$ & $\begin{array}{l}\text { Total no. of } \\
\text { polymorphic } \\
\text { allele }\end{array}$ & $\begin{array}{l}\text { Total no. of } \\
\text { Monomorphic } \\
\text { allele }\end{array}$ & Polymorphism \% \\
\hline 1. & CICER NCPGR 263 & $110-120$ & 2 & 2 & 0 & 100.00 \\
\hline 2. & CICER NCPGR 107 & $240-260$ & 3 & 3 & 0 & 100.00 \\
\hline 3. & CICER NCPGR 170 & $200-260$ & 7 & 4 & 3 & 57.14 \\
\hline 4. & CICER TA 14 & $300-310$ & 2 & 2 & 0 & 100.00 \\
\hline 5. & CICER TA 22 & $200-300$ & 11 & 7 & 4 & 63.64 \\
\hline 6. & CICER TA 27 & $110-210$ & 3 & 3 & 0 & 100.00 \\
\hline 7. & CICER TA 28 & $190-400$ & 7 & 7 & 0 & 100.00 \\
\hline 8. & CICER TA 71 & $190-250$ & 3 & 3 & 0 & 100.00 \\
\hline 9. & CICER TA 130 & $200-250$ & 6 & 5 & 1 & 83.33 \\
\hline 10. & CICER TR 29 & $140-200$ & 7 & 5 & 2 & 71.43 \\
\hline 11. & CICER TA 72 & $230-250$ & 3 & 3 & 0 & 100.00 \\
\hline 12. & CICER TR 43 & $300-390$ & 6 & 5 & 1 & 83.33 \\
\hline 13. & CICER TR 7 & $190-210$ & 3 & 3 & 0 & 100.00 \\
\hline 14. & CICER NCPGR 209 & $150-200$ & 6 & 4 & 2 & 66.67 \\
\hline 15. & CICER CAST MS2 & $60-250$ & 4 & 4 & 0 & 100.00 \\
\hline 16. & CICER CAST MS21 & 160 & 1 & 0 & 1 & 0.00 \\
\hline 17. & CICER TA 135 & $140-210$ & 8 & 6 & 2 & 75.00 \\
\hline & \multicolumn{2}{|l|}{ Total } & 82 & 66 & 16 & 80.49 \\
\hline
\end{tabular}


Table.3 Eigenvalues, differences, percentage of proportions and cumulative for first 20 principal co-ordinate axes, derived from SSR data of 66 chickpea genotypes

\begin{tabular}{|c|c|c|c|}
\hline Sr. No. & Eigenvalue & Percent & Cumulative \\
\hline 1 & 11.74677 & 18.0719 & 18.0719 \\
\hline 2 & 8.854313 & 13.622 & 31.694 \\
\hline 3 & 5.426025 & 8.3477 & 40.0417 \\
\hline 4 & 4.653225 & 7.1588 & 47.2005 \\
\hline 5 & 3.898854 & 5.9982 & 53.1987 \\
\hline 6 & 3.407169 & 5.2418 & 58.4405 \\
\hline 7 & 2.959289 & 4.5528 & 62.9933 \\
\hline 8 & 2.364898 & 3.6383 & 66.6316 \\
\hline 9 & 2.266272 & 3.4866 & 70.1182 \\
\hline 10 & 2.068324 & 3.182 & 73.3002 \\
\hline 11 & 1.814614 & 2.7917 & 76.0919 \\
\hline 12 & 1.605945 & 2.4707 & 78.5626 \\
\hline 13 & 1.457705 & 2.2426 & 80.8052 \\
\hline 14 & 1.354458 & 2.0838 & 82.889 \\
\hline 15 & 1.177392 & 1.8114 & 84.7004 \\
\hline 16 & 1.012731 & 1.558 & 86.2584 \\
\hline 17 & 0.924117 & 1.4217 & 87.6801 \\
\hline 18 & 0.845964 & 1.3015 & 88.9816 \\
\hline 19 & 0.735567 & 1.1316 & 90.1133 \\
\hline 20 & 0.709056 & 1.0909 & 91.2041 \\
\hline
\end{tabular}

Fig.1 Representative gel profiles of 66 chickpea germplasms based on SSR primers

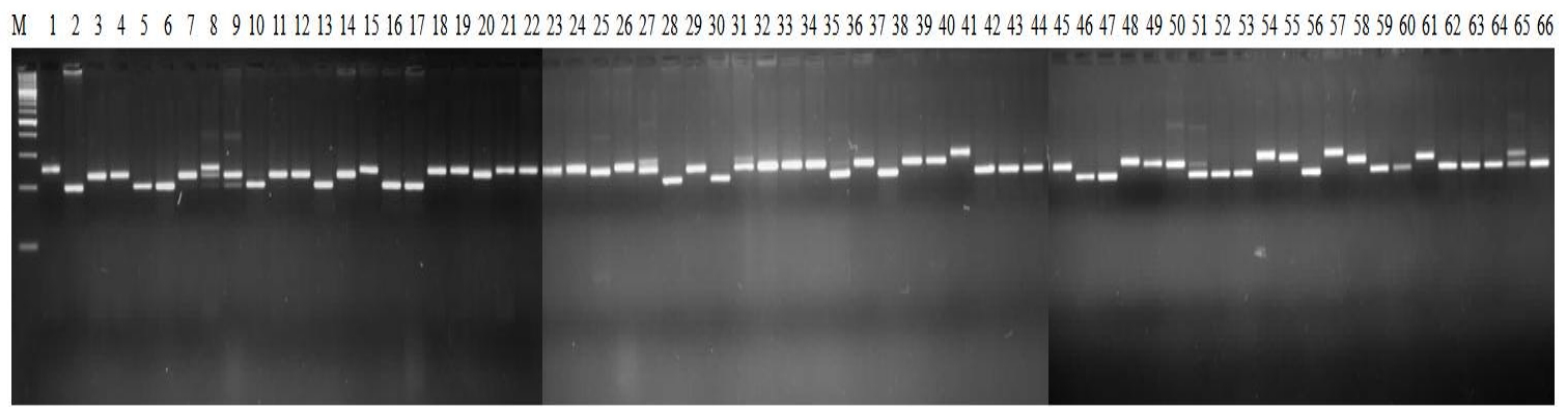


Fig.2 Dendrogram generated from SSR markers of 66 chickpea genotypes using UPGMA

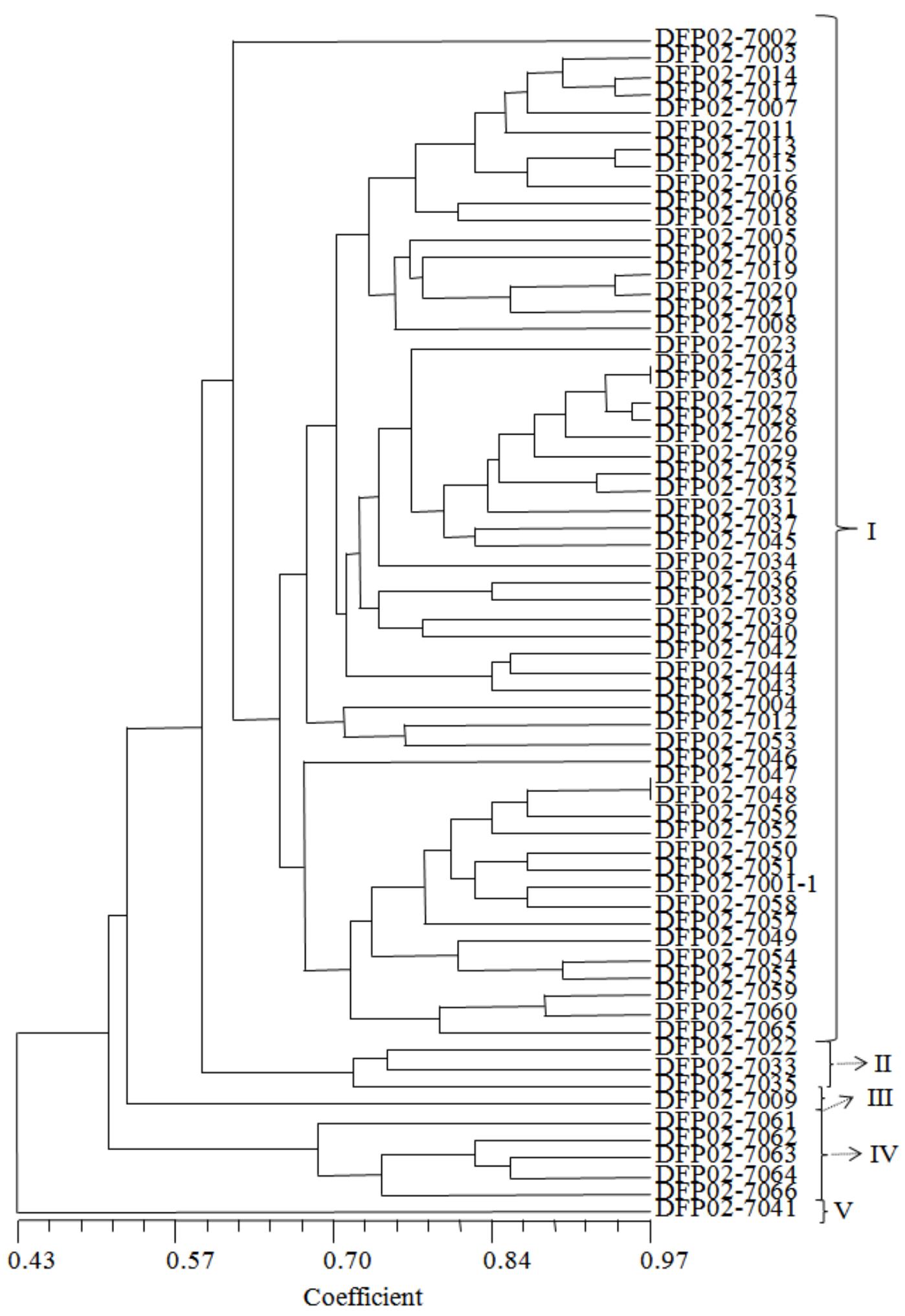


Fig.3 2-D plot of 66 chickpea genotypes generated based on principle component analysis

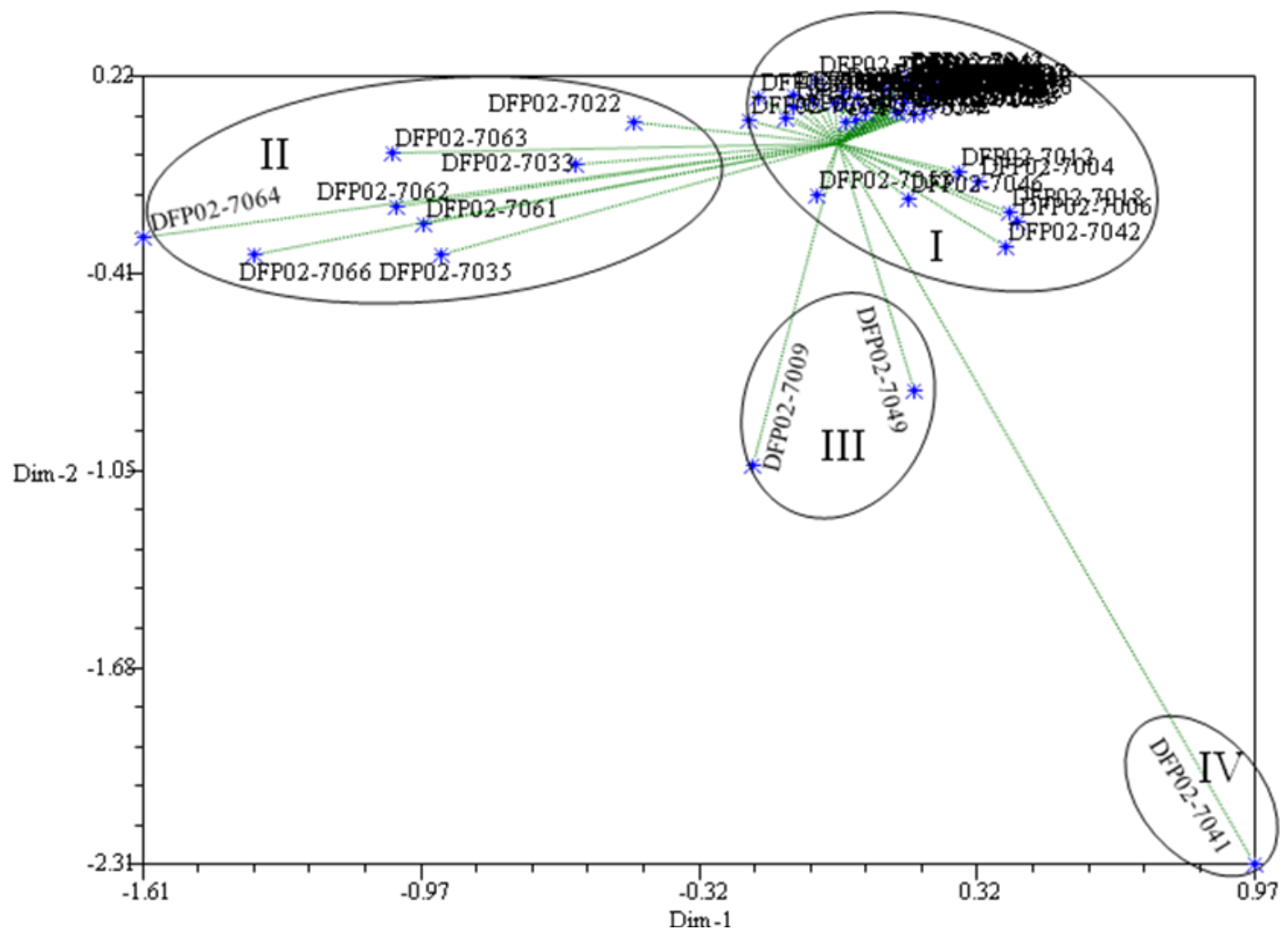

Tremendous diversity is witnessed in chickpea germplasm. Chickpea harbour significantly higher genetic diversity and these are an important reservoir of useful genes. Molecular marker based technologies have revolutionized the genetic analysis of crop plant and its application can greatly help in varietal application and genotype individualization. Molecular fingerprinting is important for their precise identification and legal protection in order to prevent their unauthorized commercial use. Besides, it would make plant breeding program more competitive and encourage public and private sector partnership. In view of the implementation of plant variety protection rights and export under WHO regulations, increasing attention is being paid towards comprehensive characterization of quality chickpea germplasm, supplementing the existing morphological descriptors with reliable and repeatable DNA based marker profiles. The advent of molecular marker technology facilities estimation of the genetic diversity and determine cultivars identity. Characterization of cultivars using DNA profiling techniques like RAPD and hyperpolymorphic microsatellite markers has been used successfully in several crop species (Bart et al., 2002; Choudhury et al., 2006; Rao et al., 2007). Among the several molecular techniques available for the detection of the genetic variability, microsatellite markers detect a high degree of polymorphism due to variation in the number of repeat units. Microsatellite marker system is considered as one of the best molecular markers for chickpea because of its co-dominant nature, simple and reproducible banding pattern, high level of polymorphism compared to other systems and also the availability of thousands of such markers on the chickpea genome. DNA profiling was done using seventeen microsatellite primer pairs distributed on all 
the sixteen chromosomes of chickpea genome. We found efficient enough to reveal usable level of DNA polymorphism among chosen genotypes. The number of bands detected by microsatellite primers varied from 2 to 7 with an average of 3.88 bands per primer.

Cluster analysis based on UPGMA using NTSYS program provided a clear resolution of relationship among all the 66 chickpea cultivars. The dendrogram broadly classified these chickpea cultivars into 5 major groups. With the availability of ultra-dense genetic and molecular linkage maps in chickpea, it is now possible to choose locus specific, highly polymorphic and co-dominant markers like microsatellite to carry out diversity and fingerprinting studies in a more structured way. Genetic diversity analysis of a large number of chickpea collections employing DNA profiling would a great deal of effort, time and cost. On the basis of the observations in the present study, it is suggested that microsatellite analysis can be efficiently utilized for this purpose. Moreover, since the markers were chosen from open reading frames of chickpea DNA, the levels of diversity exhibited by them are likely to be unbiased and not due to chance. Such specific markers would be of great value to serve DNA fingerprints for the characterization of the genetic resources of chickpea for promising traits (Sethy et al., 2006). Informative microsatellite markers are cost effective and useful in diversity analysis.

However, the present study is still at its infancy. A lot of primers from different chromosomes are required to analyze even much larger germplasm to get a reproducible data that can be used as ready references by rice breeders, variety registration authority, private agencies, etc. The investigation demonstrated the potential use of SSR analysis for assessment of varietal identification, nature and magnitude of variability, interrelationship, and conservation and for maintaining the distinctiveness of valuable germplasms.

\section{References}

Aggarwal H, Rao A, Rana JS, Singh J, Kumar A, Chhokar V and Beniwal V 2011. Inter simple sequence repeats reveal significant genetic diversity among chickpea (Cicer arietinum L.) Cultivars. J Plant Sci 6: 202-212.

Aggarwal H, Singh J, Khaket TP and Chhokar V 2013. Genetic diversity in chickpea using various molecular markers: first step towards molecular breeding. Int $\mathbf{J}$ Adv Res 1: 393-398.

Alam A, Naik PK and Mishra GP 2009. Congruence of RAPD and ISSR markers for evaluation of genomic relationship among 28 populations of Podophyllum hexandrum Royle from Himachal Pradesh, India. Turk J Bot 33: $1-12$.

Bart S, Melchinger AE and Lubberstedt $\mathrm{T}$ 2002. Genetic diversity in Arabidopsis thaliana L. Heynh investigated by cleaved amplified polymorphic sequence (CAPS) and inter-simple Sequence repeat (ISSR) markers. Mol Ecol 11: 495-505.

Choudhary S, Sethy NK, Shokeen B and Bhatia S 2006. Development of sequence-tagged microsatellites site markers for chickpea (Cicer arietinum L.). Mol. Ecol. Notes 6: 93-95.

FAO, 2013. FAOSTAT. Food and Agriculture Organization of the United Nations. Website http://faostat.fao.org/default.aspx.

ICRISAT, 2013. Chickpea (Cicer arietinum L.). Website http://www. Icrisat.org/crop-chickpea.htm.

Jukanti AK, Gaur PM, Gowda CL and Chibbar RN 2012. Nutritional quality 
and health benefits of chickpea (Cicer arietinum L.): a review. Br J Nutr 108: S11-S26.

Mantel NA 1967. The detection of disease clustering and a generalized regression approach. Cancer Res 27: 209-220.

Powell W, Morgante M, Andre C, Hanafey $\mathrm{M}$, Vogel J, Tingey S and Rafalski A 1996. The comparison of RFLP, RAPD, AFLP and SSR (microsatellite) markers for germplasm analysis. Mol Breeding 2: $225-238$.

Rao AS, Usha Rani P, Deshmukh PS, Kumar PA and Panguluri SK 2007. RAPD and ISSR ingerprinting in cultivated chickpea (Cicer arietinum L.) and its wild progenitor $C$. reticulatum $\mathrm{L}$. Genet Resour Crop Ev 54: 1235-1244.

Saeed A, Hovsepyan H, Darvishzadeh R, Imtiaz M, Panguluri SK and Nazaryan R 2011. Genetic diversity of Iranian accessions, improved lines of chickpea (Cicer arietinum L.) And their wild relatives by using simple sequence repeats. Plant Mol Biol Rep 29: 848858.

Saghai-Maroof MA, Soliman KM, Jorgensen RA and Allard RW 1984. Ribosomal DNA sepacer-length polymorphism in barley: mendelian inheritance, chromosomal location, and population dynamics. Proc Natl Acad Sci. 81:8014-8019.

Sethy NK, Shokeen B, Edwards KJ and Bhatia S 2006. Development of microsatellite markers and analysis of intraspecific genetic variability in chickpea (Cicer arietinum L.). Theor. Appl. Genet. 112: 1416-1428.

Singh PC, Prasad D, Singhal V and Randhawa GJ 2002. Analysis of genetic diversity in Cicer arietinum L. Using RAPD markers. J Plant Biochem Bioech 11: 109-112.

Sudupak MA, Akkaya MS and Kence A 2002. Analysis of genetic relationships among perennial and annual Cicer species growing in Turkey using RAPD markers. Theor Appl Genet 105: 12201228.

Talebi R, Fayaz F, Mardi M, Pirsyedi SM and Naji AM 2008. Genetic relationships among chickpea (Cicer arietinum) elite lines based on RAPD and agronomic markers. Int J Agric Bio 10: 301-305.

Varshney RK, Song C, Saxena RK, Azam S, Yu S, Sharpe AG, Cannon S, Baek J, Rosen BD, Tar'an B et al., 2013. Draft genome sequence of chickpea (Cicer arietinum) provides a resource for trait improvement. Nature Biotechnol 31: 240-248.

\section{How to cite this article:}

Harshika Aggarwal, Shiv Pratap Choudhary, M.K. Rana and Choudhary, R. 2018. Assessment or Evaluation of Genetic Diversity among 66 Cultivars of Chickpea (Cicer arietinum L.) of Indian Origin Using SSR Markers. Int.J.Curr.Microbiol.App.Sci. 7(02): 523-533. doi: https://doi.org/10.20546/ijcmas.2018.702.066 